\title{
As formas de atuação do Estado no Domínio Econômico: limites constitucionais sob a perspectiva do Poder Judiciário
}

The forms of the state interaction at the Economic Field: constitutional limits under the perspective of the Judiciary

\author{
Washington Eduardo Perozim da Silva \\ Universidade Metodista de Piracicaba (UNIMEP), \\ Piracicaba/SP - Brasil.
}

Resumo O presente artigo tem por objetivo analisar o posicionamento do Poder Judiciário em relação aos limites constitucionais estabelecidos para a intervenção do Estado no domínio econômico do país.

Para tanto - além de se apreciar, respectivamente, os conceitos de (i) Direito Econômico; (ii) Ordem Econômica; (iii) Constituição Econômica; (iv) os fatos históricos que levaram à sistematização da Ordem Econômica e Financeira no atual texto da Constituição e (v) as formas de Intervenção concebidas pela doutrina jurídica - foram objeto de estudo as decisões proferidas pelo Supremo Tribunal Federal nos julgamentos da AÇÃO DIRETA DE CONSTITUCIONALIDADE (ADI nº. 1.950) e da ARGUIÇÃO DE DESCUMPRIMENTO DE PRECEITO FUNDAMENTAL (ADPF n $\left.{ }^{\circ} .49\right)$.

Ao final se estudará, de forma breve, o fenômeno da judicialização de questões pertinentes à Ordem Econômica ocorrida nos últimos anos e a contribuição desses julgamentos para a formação de um paradigma jurisprudencial consistente.

Palavras-chave: Domínio eConômico. Intervenção. Limite Constitucional. 
Abstract The present academic work has as objective to analyze the Judiciary's position related to the established constitutional limitation for the State intervening on the economic domain of the country. In addition to studying, respectively, the concepts of (i) Economic Law; (ii) Economic Order; (iii) Economic Constitution; (iv) the historical facts that led to Economic and Financial Order systematization in the present Constitutional text and (v) the forms of intervention conceived by the legal doctrine -, was studied the decisions pronounced by the Federal Supreme Court in the judgments of the DIRECT ACTION OF CONSTITUTIONALITY (ADI No.1950) and of the ARGUITION OF FUNDAMENTAL PRECEPT OUS DISREGRADING (ADPF No. 49). In the end, the phenomenon of the judicialization of issues pertinent to the Economic Order occurred in recent years and the contribution of these judgments (you could also use trial) to the formation of a consistent jurisprudential paradigm will be succinct studied.

Key-words: EConomic dominance. InTERVEntion. Constitutional Limits.

\section{INTRODUÇÃO}

O legislador brasileiro, seguindo uma forte tendência europeia (adotada após o final da Primeira Guerra Mundial), passou a inserir no texto constitucional normas de caráter econômico.

Assim, desde 1934 dispositivos com tal natureza passaram a integrar, sistematicamente, o catálogo das Constituições do Brasil, com especial destaque para a Carta de 1988, que dedicou um título e quatro capítulos específicos para tratar da Ordem Econômica e Financeira.

Seja por meio de intervenções diretas ou indiretas, é fato incontroverso que o Estado tem atuado de forma cada vez mais contundente (planos econômicos, políticas de privatizações, incentivos fiscais, tabelamentos de preços etc.), no domínio econômico do país.

No entanto, é necessário sempre indagar-se sobre os limites dessas intervenções. Haveria alguma restrição ou o Estado, em nome do princípio da melhor eficiência e da realização da justiça social, estaria liberado para atuar no setor quando lhe fosse conveniente? 
Decorridos quase três décadas da entrada em vigor da atual Constituição Federal, a questão sobre a existência de uma limitação constitucional a essas intervenções ainda é tema dos mais controvertidos.

Encontram-se opiniões para todos os gostos. Há juristas que defendem a sua diminuição em benefício da livre regulação do mercado e, outros tantos que sustentam a figura do Estado intervencionista.

Partindo-se do princípio que todo ordenamento jurídico estabelece os seus próprios limites, qual seria a perspectiva do Poder Judiciário sobre esse tema?

Este é objetivo deste trabalho: analisar o posicionamento do Supremo Tribunal Federal em questões que envolvam as formas e limites dessas intervenções (diretas ou indiretas) do Estado na atividade econômica do país.

Para tanto, serão estudados dois julgados que ganharam grande enfoque no cenário nacional em razão da temática envolvida.

Porém, antes de se enfrentar a problemática central, serão apresentados alguns subsídios doutrinários ([i] os conceitos de Direito Econômico; de Ordem Econômica e de Constituição Econômica; [ii] os fatos históricos que levaram à sistematização da Ordem Econômica e Financeira na atual Constituição Federal; e [iii] as formas de Intervenção do Estado no domínio econômico) para que, ao término da exposição, subsistam elementos suficientes para justificar os resultados obtidos com a pesquisa.

Ao final, se apresentarão os resultados do estudo (conclusão), tendo por escopo contribuir, um pouco mais, para com o debate jurídico sobre o tema.

\section{Conceito, SuJEITos E OBJETo do direito ECONÔMiCo}

Para se alcançar o objetivo desta obra, é imprescindível dissertar, mesmo que rapidamente, sobre o conceito; os sujeitos e o objeto do Direito Econômico.

Vicente Bagnoli (2013, p. 23) o conceitua como um ramo autônomo do Direito que tem por objeto o estudo do desenvolvimento da 
política econômica do Estado e da relação entre os particulares para alcançar o desenvolvimento socioeconômico:

(...) pode-se definir que o Direito Econômico é a disciplina autônoma Direito, interdisciplinar jurídica e econômica, que se ocupa do tratamento jurídico da política econômica do Estado e da relação entre os indivíduos e os agentes de mercado, para alcançar o bem-estar social e, consequentemente desenvolver o desenvolvimento socioeconômico, a partir da utilização do princípio da economicidade, traduzindo o conceito de eficiência em justiça.

João Bosco Lepoldino da Fonseca (2010, p. 8) complementa o conceito de Bagnoli ao dissertar que a diferença desse ramo do Direito (Direito Econômico) em relação aos demais remanesceria, exatamente, o seu campo de atuação, de estudo, ou seja, o seu aspecto formal, haja vista que um de seus principais focos encontra-se, justamente, nas "políticas econômicas" adotadas pelo Estado (ao longo do tempo) para o desenvolvimento socioeconômico de uma nação:

(...) O Direito, enquanto ciência, se dedica ao estudo das relações intersubjetivas, sob o aspecto normativo. Mas ainda há outro aspecto, o formal, a configurar e delimitar o campo de estudo. Como visto acima, o Direito pode estudar as normas que regem aquelas relações sob vários prismas. Um deles é o da direção política econômica pelo Estado. Ser este o aspecto que identificará e distinguirá o Direito Econômico dos demais ramos jurídicos.

Já Washington Peluso Albino de Souza (2003, p. 23) afirma que o Direito Econômico não poderia ser considerado um ramo, mas, sim, um conjunto de normas de conteúdo econômico que, entre outras coisas, permitiriam a defesa e a harmonia dos interesses individuais e coletivos, de acordo com a ideologia adotada na ordem jurídica. 
Outros doutrinadores, como Fabiano Del Masso (2016, p. 8), o definem "como a reunião das normas que regulam a estrutura (Ordem Econômica) e as relações entre os agentes econômicos na realização da atividade econômica".

Por derradeiro, vale citar a classificação de Fernando Herren Aguillar (2016, p. 1), que o define como o direito das políticas públicas na economia, representado por um conjunto de normas e institutos jurídicos a serviço do Estado para que este possa atuar (legalmente) na macro e microeconomia de determinado país.

Apresentado o "conceito", torna-se mais fácil identificar e discorrer sobre os seus sujeitos e objeto.

Assim, podem ser considerados sujeitos do Direito Econômico: os Estados; os agentes econômicos que atuam no mercado; as empresas; grupos econômicos; organismos (nacional ou internacional, de direito público ou privado); bem como, o próprio indivíduo; enquanto que a "realização da justiça" (BAGNOLI, 2013, p. 22), por meio da implementação e execução de políticas econômicas, seria o seu principal objeto.

Identificados todos os elementos (conceito, objeto e sujeitos) que fundamentam esse ramo do Direito, faz-se imprescindível discorrer sobre o significado e a utilização no discurso jurídico da expressão Ordem Econômica.

\section{O SIGNIFICADO E A UTILIZAÇÃO DA EXPRESSÃO ORDEM ECO- NôMICA NO DISCURSO JURÍDICO}

A expressão ordem econômica é comum no universo do Direito e, ao longo dos anos, vem sendo utilizada como sinônimo de um sistema de normas criado para a regulamentar as políticas públicas e as relações entre Estado/particulares e agentes de mercado/particulares etc.

Contudo, para a melhor compreensão e aproveitamento, é necessário considerar os diferentes significados através dos quais o vocábulo é empregado pelos doutrinadores. 
Eros Grau (2015, p. 65) vale-se dos ensinamentos de Vital Morei$\mathrm{ra}^{1}$ para explicar as diferenças existentes entre os três tipos de designação, geralmente utilizados nos textos jurídicos:

(...) em um primeiro sentido, 'ordem econômica' é o modo de ser empírico de uma determinada economia concreta; a expressão, aqui, é termo de um conceito de fato e não de um conceito normativo ou de valor (é conceito do mundo do ser, portanto); o que caracteriza é a circunstância de referir-se não a um conjunto de regras ou normas reguladoras de relações sociais, mas sim a uma relação entre fenômenos econômicos e materiais, ou seja, relação entre fatores econômicos concretos; conceito do mundo do ser, exprime a realidade de uma inerente articulação do econômico com o fato; em um segundo sentido, 'ordem econômica' é expressão que designa o conjunto de todas as normas (ou regras de conduta), qualquer que seja a sua natureza (jurídica, religiosa, moral, etc.), que respeitam à regulação do comportamento dos sujeitos econômicos; é o sistema normativo (no sentido sociológico) da ação econômica; em um terceiro sentido, 'ordem econômica' significa ordem jurídica na economia.

No entendimento do autor citado, não se faria possível, como também, não se deveria confundir as três modalidades em que a expressão poderia ser utilizada, haja vista a essência e o significado de cada uma delas.

A primeira corresponderia ao modo de ser de uma economia, ou seja, seria constituída pelos princípios e modelo econômico (regime) adotados por determinado país (o capitalismo nos Estados Unidos da América do Norte, o socialismo em Cuba etc.).

A segunda, equivaleria ao conjunto de normas (independentemente da natureza) que regulariam ação econômica dos sujeitos (Estado/ particulares; particulares/agentes de mercado etc.), enquanto que a terceira teria por significado a própria ordem jurídica da economia.

1 A Ordem Jurídica do Capitalismo, Coimbra, Centelha, 1973, p. 67-71. 
Anote-se que, para o festejado doutrinador, quando inserida em um contexto jurídico, a expressão deveria ser empregada para indicar uma parcela do ordenamento jurídico, não havendo justificativas para o uso inapropriado.

E, seguindo essa linha de raciocínio, o mesmo autor apresenta um modelo ou, melhor dizendo, um arquétipo do que poderia ser considerado Ordem Econômica:

(...) Em outra ocasião, a descrevi como conjunto de princípios jurídicos de conformação do processo econômico, desde uma visão macrojurídica, conformação que se opera mediante o condicionamento da atividade econômica a determinados fins políticos do Estado. Tais princípios - prossegui - gravitam em torno de um núcleo, que podemos identificar nos regimes jurídicos da propriedade e do contrato (GRAU, 2015, p. 68).

Nesse aspecto, André Ramos Tavares (2011, p. 83) lembra que a expressão poderia ser concebida como a de "certo arranjo econômico", dentro de um sistema específico, preordenado juridicamente.

Del Masso (2016, p. 44) disserta que a Ordem Econômica corresponderia a uma representação estrutural que teria por objetivo organizar a realização da atividade econômica em determinada comunidade.

Pelos posicionamentos apresentados, entende-se que a conotação atribuída para a expressão está longe de qualquer unanimidade, sendo (sempre) necessário contextualizar o público, o local e o momento em que a mesma é empregada para identificar o seu real significado.

Superada a questão sobre o uso e o significado do vocábulo, importa, agora, apresentar os elementos históricos (políticos e jurídicos) que contribuíram para a sua sistematização no atual texto constitucional.

\section{A sistematização da ordem econômica na atual Cons- TITUIÇÃo FEDERAL - A CONSTITUIÇÃo ECONÔMICA}

O liberalismo do século XIX, em razão das grandes distorções sociais resultantes de sua concepção ideológica e da sua forma de exe- 
cução, foi aos poucos perdendo espaço entre as nações que o adotaram como regime econômico.

Desde 1891, ano marcado pela encíclica papal Rerum novarum, de autoria do papa Leão XIII, ${ }^{2}$ até o início da Primeira Guerra Mundial, inúmeras discussões - sobre a estrutura e eficácia do modelo liberal defendido por Adam Smith - foram travadas, pois já não se concebia mais a ideia de um Estado totalmente ausente ou pouco participativo das questões econômicas, uma vez que a autorregulação do mercado mostrava-se incapaz de garantir o equilíbrio social.

Com o armistício de 1918, o antigo sistema econômico mostrava-se totalmente desgastado. Para se ter uma ideia do cenário europeu da época, basta lembrar que a Rússia enfrentava uma revolução socialista sem precedentes, e os demais países envolvidos no conflito, em especial a Alemanha, encontravam-se afundados em grave crise social/financeira.

Todos esses ingredientes históricos e políticos impulsionariam o fim do liberalismo econômico, representado pela fundação da República de Weimar ${ }^{3}$ (1918-1933) e na sua Carta Constitucional, promulgada em 31 de julho de 1919:

(...) A Constituição de Weimar é aquela em que se observa pela primeira vez o Direito Econômico, ou seja, o Estado, em sua Lei maior, ditando regras e princípios para que o fenômeno econômico no mercado encontrasse limites e garantias para atender a sociedade e assegurar a justiça social.

O capítulo que instaura a vida econômica na Constituição de Weimar, art. 151, tem como princípio o limite à liberdade de mercado a fim de preservar um nível de existência em atenção à dignidade humana (BAGNOLI, 2013, p. 13).

2 "É necessário, com medidas prontas e eficazes, vir em auxílio dos homens das classes inferiores, atendendo a que eles estão, pela maior parte, numa situação e de miséria imerecida."

3 Com o fim da Primeira Guerra Mundial, surge a primeira República Alemã, a qual foi instituída pela constituição elaborada e votada na cidade saxônica de Weimar. 
No entanto, o fenômeno jurídico não foi primazia da nação alemã, haja vista que, poucos anos antes, a Constituição Mexicana (1917) havia sido a primeira a "atribuir a qualidade de direitos fundamentais aos direitos trabalhistas, além das liberdades individuais e direitos políticos" (BAGNOLI, 2013, p. 12).

Seguindo o exemplo do México e da Alemanha, outros países passaram a inserir temas de natureza econômica (artigos, títulos e capítulos) em suas Cartas.

Ou seja, as nações deixaram de lado o modelo liberal (estabelecido no século XIX) e adotaram uma nova forma de atuação do Estado; deixando o mesmo de ser um mero coadjuvante para exercer a função de protagonista no desenvolvimento econômico dos países.

Para tanto, o Estado passou a editar normas e integrou, definitivamente, a ordem jurídica à ordem econômica, circunstância que resultaria, no entender de Bagnoli (2013, p. 44), em uma "Ordem-Jurídico-Econômico".

Estava estabelecido, então, o instituto jurídico que passou a ser denominado como Constituição econômica "A idéia de Constituição Econômica, ganhou corpo na doutrina alemã, neste século, a partir da conseração do quanto dispôs a Constituição de Weimar a respeito da vida econômica" (GRAU, 2015, p. 77).

Fonseca (2010, p. 37) ensina que a Constituição econômica corresponderia a um conjunto de instituições e normas destinadas a regulamentar a atividade econômica em constante mutação:

(...) O conjunto das instituições e das normas destinadas a reger a atividade econômica sempre renovada, sempre insurgente contra as vinculações jurídicas, se solidifica num contexto significante a que se dá o nome de constituição econômica.

O jurista português Vital Moreira (1974, p. 35-36) leciona que o conceito de Constituição econômica deveria ser compreendido de forma ampla, incluindo-se, além da norma constitucional, todos os institu- 
tos legais (infraconstitucionais) que visam regulamentar a vida econômica de um país:

(...) Assim, da CE de, por exemplo, uma economia capitalista orientada, fazem parte não só as normas que asseguram a propriedade e disposição privada dos meios de produção e outros diretos fundamentais econômicos (liberdade de empresa, liberdade de trabalho), mas também aquelas que determinam o papel do mercado e do estado na orientação do processo econômico, aquelas de definem os princípios fundamentais da organização econômica strictu sensu (associações econômicas), das finanças, do estado, sob o ponto de vista de sua relevância econômica ('constituição financeira'), do estatuto da empresa nos seus aspectos externos e internos ('constituição da empresa'), da posição do trabalhador ('constituição do trabalho').

No entanto, Tavares (2011, p. 77) discorda do doutrinador lusitano ao afirmar que só poderia ser considerada econômica, aquela constituição que guardasse (formalmente) em seu texto uma parcela de normas que interpretassem e regulassem o sistema econômico material:

(...) Pode-se considerar a Constituição econômica formal como a parcela da Constituição que abriga e interpreta o sistema econômico (material), ou seja, lhe confere forma ao sistema econômico (no caso brasileiro, em sua essência capitalista). A constituição econômica formal brasileira consubstancia-se na parte da Constituição Federal que contém os direitos que legitimam a atuação dos sujeitos econômicos, o conteúdo e limites desses direitos e a responsabilidade que são inerentes na atividade econômica do país.

Ainda na visão de Bagnoli (2016, p. 12), seria considerada Constituição econômica toda a Carta que possuísse em seu bojo, artigos ou capítulos que atribuíssem sentido jurídico ao tema econômico: 
(...) Entendem-se constituições econômicas todas a Cartas que possuem em artigos esparsos de seu texto ou em títulos ou capítulos específicos temas econômicos, ou seja, atribuir ao tema econômico sentido jurídico. Daí a configuração da orem jurídico econômica e suas modernas denominações: ordem econômica e social, ordem econômica e financeira ou, tão somente, ordem econômica.

O Brasil, seguindo os acontecimentos que marcavam o cenário mundial daquele período, inseriu no texto constitucional de 1934 um grupo de normas de natureza econômica (artigos 115 a 140), adotando, assim, o instituto em sua Lei maior.

Todavia, foi no texto da Carta de 1937, que se atribuiu um título específico para essa modalidade de dispositivos, denominado Da Ordem Econômica:

(...) A redação do art. 135 da Constituição, que encabeça o capítulo sobre a Ordem Econômica, tem caráter verdadeiramente didático, estatuindo que 'na iniciativa individual, no poder de criação, de organização e de invenção do indivíduo, exercido nos limites do bem público, funda-se a riqueza e a prosperidade nacional. A intervenção do Estado no domínio econômico só se legitima para suprir as deficiências da iniciativa individual e coordenar os fatores da produção, de maneira a evitar ou resolver os seus conflitos e introduzir no jogo das competições individuais o pensamento e os interesses da nação, representados pelo Estado. A intervenção no domínio econômico poderá ser mediata ou imediata, revestindo a forma do controle, do estímulo ou da gestão direta' (AGUILLAR, 2016, p. 135-136).

A Constituição de 1946, que marcou um período de redemocratização do país, trouxe em um de seus títulos a seguinte denominação $D a$ Ordem Econômica e Social, reunindo, pela primeira vez, artigos com temática social e econômica. 
Em 1967, já sob a égide de um governo militar, o texto constitucional também tratou de temas econômicos. Naquela ocasião, ou melhor dizendo, desde a revolução de 1964, a segurança nacional passou a ser a principal prioridade do governo instituído, circunstância histórica que resultaria na "formação ideológica segundo a qual a segurança é a raiz do desenvolvimento econômico, social e político" (DEL MASSO, 2016, p. 53).

A Emenda Constitucional $\mathrm{n}^{\circ} .01$ de 1969, por sua vez, admitiu o direito à greve (exceto no serviço público e essenciais) e "delimitou a competência dos setor privado e estatal econômicos na organização e exploração da atividade econômica, assegurando ao Estado a sua atuação ou intervenção no domínio econômico" (BAGNOLI, 2013, p. 62).

A atual Constituição da República (promulgada em 05-10-1988) destaca-se pelo aspecto social e econômico; pela sua preocupação com o cidadão e, pela importância que é atribuída ao Estado no desempenho de suas funções.

Contudo, em relação às anteriores, ela trouxe mais uma inovação e, pela primeira vez na história constitucional, utilizou-se no texto legal a expressão Ordem Econômica e Financeira.

Dos fatos narrados, pode-se concluir que o paulatino processo de sistematização da Ordem Econômica na história das Constituições brasileiras decorreu de momentos políticos e das mudanças sociais enfrentadas durante os respectivos períodos, levando em consideração, muitas vezes, situações políticas e jurídicas totalmente estranhas à realidade nacional; advindas de outros países e de suas legislações, mas, em certo aspecto, aplicáveis, já que, na realidade, nenhuma Ordem Econômica possui características tão específicas a ponto de individualizá-las.

Conhecidos os acontecimentos históricos que resultaram na sistematização da Constituição Econômica no Brasil, viabiliza-se a análise - com mais propriedade - da Ordem Jurídica Econômica inserida no atual texto constitucional. 


\section{A ordem econômica estabelecida na atual Constitui- ÇÃo FEDERAL}

Conforme já explicitado, a atual Constituição da República se destaca pelo "aspecto social e enfoque com que trata o cidadão, bem como, no campo econômico, pelo novo foco que é atribuído ao Estado no desempenho de suas funções" (BAGNOLI, 2013, p. 64).

Aliás, a Carta em vigência, como todas as demais, é produto da "ideologia de sua época de forma a instituir o sistema econômico nacional com base em uma economia descentralizada, portanto, o papel do mercado volta a representar importante controle de atividade econômica" (DEL MASSO, 2016, p. 57).

Assim, seguindo uma tendência ideológica, a Ordem Social foi apartada da Ordem Econômica e esta, por sua vez, no texto atual, foi conjugada com a Ordem Financeira, estabelecida no Título VII ( $D a$ Ordem Econômica e Financeira), composta de quatro capítulos: I - Princípios gerais da atividade econômica (artigos 170 a 181); II Política urbana (artigos 182 a 183); III - Política agrícola e fundiária e da reforma agrária (artigos 184 a 191); e IV - Sistema financeiro nacional (artigo 192).

André Ramos Tavares (2011, p. 120) afirma que a disciplina da atividade econômica na atual Constituição (embasada em um postulado de caráter capitalista) foi realizada de forma minuciosa e sem precedentes.

Eros Grau (2016, p. 187-188), após analisar o posicionamento de inúmeros autores, assim descreveu as características da Ordem Econômica estabelecida na Constituição de 1988:

(...) A ordem econômica na Constituição de 1988 consagra um regime de mercado organizado, entendido como tal aquele afetado pelos preceitos da ordem pública clássica (Geraldo Vidigal); opta pelo tipo liberal do processo econômico, que só admite a intervenção do Estado para coibir abusos e preservar a livre concorrência de quaisquer interferências, quer do próprio Estado, quer no embate econômico que pode levar à formação de monopó- 
lios e ao abuso do poder econômico visando ao aumento arbitrário dos lucros - mas sua posição corresponde à do neoliberalismo (Miguel Reale); (note-se que a ausência do vocábulo 'controle' no texto do art. 174 da Constituição assume relevância na sustentação dessa posição.

A ordem econômica na Constituição de 1988 contempla a economia de mercado, distanciada, porém, do modelo liberal puro e ajustada à ideologia neoliberal (Washington Peluso Albino de Souza); a Constituição repudia o dirigismo, porém acolhe o intervencionismo econômico, que não se faz contra o mercado, mas a seu favor (Tércio Sampaio Ferraz Júnior); a Constituição é capitalista, mas a liberdade apenas é admitida quando exercida no interesse da justiça social e confere prioridade aos valores do trabalho humano sobre todos os demais valores da economia de mercado (José Afonso da Silva);

A constituição consagra a 'estatolatria' (Manoel Gonçalves Ferreira Filho); o constituinte preferiu o modelo - rígido ortodoxo - que conduz ao dirigismo econômico (Raul Machado Horta).

Além disso - consideradas as circunstâncias de poder a Constituição ser interpretada dinamicamente e de ser ela um dinamismo -, as seguintes verficações alinhadas:

- apesar de a Constituição ser capitalista, abre caminho à transformação da sociedade (José Afonso da Silva); - há, na Constituição, cláusulas transformadoras que poderão conduzir ao intervencionismo, ao dirigismo, ao nacionalismo e à estatização (Raul Machado Horta); - quanto ao art. 174, 'será fácil distorcer essas diretrizes, convertendo-se fiscalização em interferência sistemática; incentivo em favorecimento e planejamento indicativo em programa (sic) obliquamente complulsórios...' (Miguel Reale).

Além das considerações apresentadas pelo doutrinador citado, não se pode esquecer que um ordenamento sempre será pautado por princípios e normas positivadas (cogentes ou programáticas). 
No caso, os princípios que norteiam a Ordem Econômica prevista na atual Constituição encontram-se estabelecidos, em sua grande maioria, no próprio artigo 170 :

(...) $\mathrm{O}$ artigo 170 traça a estrutura geral do ordenamento jurídico econômico. Este tem como fundamento a valorização do trabalho humano e a livre iniciativa. Aceitos tais fundamentos, a Constituição estabelece a finalidade de toda a atuação através de políticas econômicas, qual seja a de assegurar a todos existência digna conforme os ditamentes da justiça social. Para que os fundamentos sejam concretizados e para que os fins sejam alcançados, necessário se faz adotar alguns princípios norteadores da ação do Estado. Surgem, ao lado de princípios já consagrados, alguns outros que decorrem das tentencias modernas (FONSECA, 2010, p. 92-93).

Portanto, a atual Ordem Econômica nacional tem por fundamentos (previstos no caput do artigo em comento): (i) a valorização do trabalho humano e (ii) a livre iniciativa, além de se encontrar pautada nos princípios da soberania nacional (inciso I); da propriedade privada (inciso II); da função social da propriedade (inciso III); da livre concorrência (inciso IV); da defesa do consumidor (inciso V); da defesa do meio ambiente (inciso VI); da redução das desigualdades regionais e sociais (inciso VII); da busca pelo emprego (inciso VIII), da defesa das empresas de pequeno porte (inciso IX), além, é claro, do princípio da dignidade da pessoa humana estabelecido no artigo $1^{\circ}$. da Constituição.

De igual modo, encontra-se no referido artigo 170 uma norma de caráter programático, ${ }^{4}{ }^{5}$ onde o Estado deixa de ser um mero coadju-

4 Segundo Vicente Bagnoli (2013, p. 47) “as normas programáticas são aquelas constitucionalmente estabelecidas que estabelecem princípios a serem respeitados e cumpridos para a consecução dos fins sociais almejados pelo Estado".

5 José Afonso da Silva (2015, p. 135) apud J. H. Meirelles Teixeira para explicar o conceito de norma programática: “(...) aquelas normas constitucionais através das quais o constituinte, em vez de regular, direta e imediatamente, determinados interesses, limitou-se a traçar-lhes os princípios para serem cumpridos pelos seus órgãos (...), como programas das respectivas atividades, visando à realização dos fins sociais do Estado". 
vante e ganha destaque como protagonista junto à atividade econômica nacional; devendo, entre outras tantas, criar condições propícias para a geração de trabalho, circulação de riquezas e, via de consequência, concretizar a justiça social:

(...) O Estado, portanto, atuando junto à economia deve criar as condições para a geração de trabalho, de modo que o indivíduo esteja inserido no mercado e o seu trabalho valorizado; afinal é por meio do trabalho que o indivíduo de forma digna participará da repartição das riquezas dentro do mercado. O trabalhador também é consumidor, fazendo a riqueza circular. Da mesma forma, o Estado deve criar todas as condições para a livre iniciativa atuar nos mercados, conferindo não só a segurança jurídica necessária para o indivíduo empreender, mas também toda a infraestrutura necessária para estimulá-lo a empreender e, com isso, promover a circulação das riquezas. Com esses fundamentos respeitados e respeitando-se os princípios da ordem econômica, tais como propriedade privada e função social, livre concorrência, defesa do consumidor e do meio ambiente, assegura-se a existência digna e promove-se a justiça social, ou seja, que cada indivíduo possa dignamente exercer uma atividade laboral ou empreender e consequentemente participar da repatriação das riquezas geradas e circuladas no mercado, fazendo-se assim justiça para a consagração do bem comum (BAGNOLI, 2013, p. 77).

José Afonso da Silva (2015, p. 138-139) retrata a necessidade de se estabelecer normas programáticas, como a existente no dispositivo legal, para fins de, dentro de um sistema no qual predomina a concentração de riqueza, se assegurar uma existência digna à coletividade:

(...) As normas programáticas são de grante importância, como dissemos, porque procuram dizer para onde e como se vai, buscando atribuis fins ao Estado, esvaziado pelo liberalismo econômico. Essa característica teleológica lhes confere relevância e função de princí- 
pios gerais de toda ordem jurídica, com bem assinala Natoli, tendente a instaurar um regime de democracia substanacial, ao determinarem a realização dos fins sociais, através da atuação de programas de intevenção na ordem econômica, com vista a assegurar a todos existência digna conforme os ditames da justiça social. Esta é o fim que os arts. 170 e 193 da Constituição de 1988 prescrevem para as ordens econômicas e social. Não é fácil realizar a justica social num sistema em que predomina a conservação de riqueza. É que ela só se concretizará mediante equitativa distribuição de riqueza nacional, pois um regime de justiça social será aquele em que cada um deve poder dispor dos meios materiais para viver confortavelmente segundo as exigências de sua natureza física, espiritual e política.

Já Fonseca (2010, p. 70-71) afirma que a principal finalidade de uma norma programática é a de criar objetivos para o Estado, a fim de que se promova uma nova realidade social, mediante a implementação de políticas públicas.

Como se constata, a Ordem Econômica prevista no atual texto constitucional criou verdadeira obrigação e, de simples fiscalizador, o Estado passou a ser o responsável pela transformação social por meio das suas intervenções no domínio econômico.

Contudo, dentro dos preceitos constitucionais estabelecidos pelo legislador, quais são as formas do Estado atuar na área econômica?

Em razão da indagação citada, torna-se obrigatório conhecer as espécies de atuação (intervenção) do Estado no setor econômico.

\section{As FORMAS DE ATUAÇão do ESTAdo NO DOMínio ECONÔMICO}

Os fatos já apresentados demonstraram como o Estado, ao longo da história política e jurídica do país, deixou de ser um mero espectador (nos tempos do Império) ou um simples coadjuvante (nos primórdios da República), para se tornar um dos principais protagonistas da atividade econômica do país. 
Hoje, por força das normas inseridas nos artigos 170 e seguintes, da Constituição Federal, se atribuiu a ele (Estado) um poder/dever não só de fiscalização, mas também de participação (efetiva) no domínio econômico, ${ }^{6}$ tendo por objetivo final a concretização da justiça social.

Segundo Bagnoli (2013, p. 107), são várias as formas de atuação, entre as quais, pode-se destacar (i) aquelas em que o Estado participa mais intensamente, como no caso dos monopólios e serviços públicos ou (ii) nas hipóteses em que exerce somente funções de normatizador e fiscalizador do setor:

(...) O Estado pode atuar de várias formas no domínio econômico, diretamente como agente econômico, controlando e fiscalizando a atuação de entes particulares, ou ainda, em parceria com a iniciativa privada. A atuação do Estado pode ser mais intensa quando Estado é o próprio agente de um setor da economia, muitas vezes até como monopolista, e menos direta quando o Estado deixa a atividade ser explorada pelo agente privado e reserva-se o poder de fiscalização. Pode também estar ausente da economia, nos moldes do liberalismo smithiano, em que o próprio mercado regularia a economia, mas esse modelo comprovadamente pela história não é eficaz, fazendo-se necessária a atuação no Estado no domínio econômico.

Fonseca (2010, p. 207) classifica essas formas de atuação estatal em direta e indireta:

(...) Como visto, as formas ou modalidades pelas quais o Estado intervém no setor econômico são diversas e cada uma delas pode assumir as mais amplas esfumaturas. Vimos que o Estado pode atuar diretamente no domínio econômico, e pode atuar só indiretamente. No

6 “(...) domínio econômico é precisamente o campo da atividade econômica em sentido estrito, área alheia à esfera pública de titularidade [domínio] do setor privado" (GRAU, 2015, p. 142-144). 
primeiro caso, assume a forma de empresas públicas propriamente ditas e as sociedades de economia mista, assim mencionadas no art. $173, \S \S 1^{\circ}, 2^{\circ}$ e $3^{\circ}$, da Constituição Federal. No segundo caso, atuação indireta, o Estado o faz através de normas, que tem como finalidade fiscalizar, incentivar ou planejar; o planejamento, como se verá, é somente indicativo para o setor privado. Esta forma de atuação do Estado está prevista no art. 174 da Constituição Federal (FONSECA, 2010, p. 107).

Anote-se que para elaborar tal classificação, o autor mencionado levou em consideração as normas inseridas, respectivamente, nos artigos $173^{7}$ (atuação direta) $174,{ }^{8}$ ambos do texto constitucional:

(...) Ao se referir à intervenção direta, a Constituição
trata-a como exploração da atividade econômica pelo
Estado e, ao se referir à intervenção indireta, toma o
Estado como agente normativo e regulador da atividade
econômica. Ambas as modalidades intervencionistas

7 art. 173. Ressalvados os casos previstos nesta Constituição, a exploração direta de atividade econômica pelo Estado só será permitida quando necessária aos imperativos da segurança nacional ou a relevante interesse coletivo, conforme definidos em lei. $\S 1^{\circ}$. A lei estabelecerá o estatuto jurídico da empresa pública, da sociedade de economia mista e de suas subsidiárias que explorem atividade econômica de produção ou comercialização de bens ou de prestação de serviços, dispondo que: I - sua função social e formas de fiscalização pelo Estado e pela sociedade; II - a sujeição ao regime jurídico próprio das empresas privadas, inclusive, quanto aos direitos e obrigações civis, comerciais, trabalhistas e tributários; III - licitação e contratação de obras, serviços, compras e alienações, observados os princípios da administração pública; IV - a constituição e o funcionamento dos conselhos de administração e fiscal com a participação de acionistas minoritários. V - os mandatos, a avaliação de desempenho e a responsabilidade dos administradores. $\S 2^{\circ}$. As empresas públicas e as sociedades de economia mista não poderão gozar de privilégios fiscais não extensivos ao setor privados. $\S 3^{\circ}$. A lei regulamentará as relações da empresa pública com o Estado e a sociedade.

(...).

8 art. 174. Como agente normativo e regulador da atividade econômica, o Estado exercerá, na forma da lei, as funções de fiscalização, incentivo e planejamento, sendo este determinante para o setor público e indicativo para o setor privado. 
constituem fórmulas pelas quais o Poder Público ordena, coordena e se faz presente na seara econômica, tendo em vista a manutenção de seus fundamentos, a realização de seus objetivos, o respeito e execução de seus demais princípios, especialmente o pleno desenvolvimento nacional tendente a eliminar o desemprego (TAVARES, 2011, p. 275).

Nos posicionamentos doutrinários apresentados até aqui, constata-se certa preferência em se atribuir a essas formas de atuação (direta ou indireta) a denominação de intervenções.

Então, se consideraria intervenção direta aquela situação jurídica em que o Estado exerceria a função de empresário, envolvendo-se, efetivamente, na atividade produtiva, seja na qualidade de empresa pública, seja na forma de sociedade de economia mista ou, ainda, como gestor da empresa privada (como ocorre nos casos em que o Banco Central assume a direção de instituições financeiras privadas e públicas [não federais] com o objetivo de regularizar o seu funcionamento ou de liquidá-las):

(...) Através da atuação direta o Estado passa atuar como empresário, comprometendo-se com a atividade produtiva, quer sob a forma de empresa pública, quer sob a de sociedade de economia mista. Sob estas duas formas pode ele atuar em regime concorrencial, em que se equiparará com as empresas privadas, ou em regime monopolístico. Como exemplo do primeiro caso (regime concorrencial) podem ser apontados o da Caixa Econômica Federal e do Banco do Brasil, a primeira, como empresa pública federal, e o segundo, como sociedade de economia mista, atuam em regime de concorrência dom as demais entidades bancárias do País. Como exemplo do segundo caso, devem-se se considerar (...) e a Petróleo Brasileiro S/A, (...), e a segunda como sociedade de economia mista. (...)

A intervenção direta pode fazer-se ainda por outro caminho: o Estado assume a gestão da empresa privada, 
passando a dirigi-lo quando interesses de ordem social o exijam. Caso específico desta forma de intervenção é a prevista na Lei n. 6.024, de 13.03.74, em que o Banco Central do Brasil assume a direção de instituições financeiras privadas e públicas não federais, com o intuito de normalizar o seu funcionamento ou, se isso for inviável, de decretar e realizar a sua liquidação extrajudicial (FONSECA, 2010, p. 207).

Deste modo, se tomaria por intervenção indireta aquela situação jurídica em que o Estado atuaria somente como um condutor, um incentivador da atividade econômica entre os particulares, mediante a criação e implementação de políticas econômicas:

(...) Ao atuar indiretamente na condução, no estímulo e no apoio da atividade econômica empreendida entre os particulares, o Estado adota determinadas formas de política econômica, peculiares a cada campo de atuação. A política econômica tem como objetivos fundamentais, nos países desenvolvidos, assegurar o crescimento sustentado da economia, assegurar o pleno emprego dos fatores de produção, particularmente da mão de obra, uma relativa estabilidade de preços e, garantir o equilíbrio da balança de pagamentos (FONSECA, 2010, p. 209).

Bagnoli (2013, p. 107), ao dissertar sobre o assunto, apud Marçal Justen Filho, para lembrar que a modalidade indireta de atuação também pode receber a denominação de intervenção normativa:

(...) A intervenção indireta ou normativa do Estado na ordem econômica, explica Marçal Justen Filho (2005, p. 456), 'consiste no exercício pelo estado de sua competência legislativa e regulamentar para disciplinar o exercício de atividades econômicas, desempenhada na órbita pública ou privada. Seu fundamento constitucional direto está no artigo 174'.

Já a intervenção direta do Estado na ordem econômica, prossegue Marçal Justen Filho (2005, p. 457), 'é o 
desenvolvimento por meio de uma entidade administrativa de atividades de natureza econômica, em competição com particulares ou mediante atuação exclusiva'.

Contudo, a doutrina não é unânime em relação à utilização do vocábulo intervenção para designar genericamente as formas de atuação do Estado.

Para Fabiano Del Masso (2016, p. 79-80), essa denominação (usada corriqueiramente pela maioria dos estudiosos do tema) não faria jus à realidade, nem tampouco ao seu sentido técnico, ou seja, não poderia ser tratada como sinônimo de atuação estatal, pois a última expressão deveria ser entendida e utilizada em seu mais alto grau de generalidade.

O último autor afirma que deveria denominar-se atuação estatal apenas a forma genérica de participação (direta ou indiretamente), seja na prestação de serviços públicos; na constituição de empresas estatais para exploração direta da atividade, ou até mesmo na criação de agências reguladoras independentes; enquanto que o vocábulo intervenção deveria ser utilizado somente para as formas indiretas, como nos casos de normatização ou fiscalização de um setor da economia:

(...) Atuação Estatal - forma genérica para se referir a qualquer tipo de participação do Estado no domínio econômico, seja prestando serviços públicos, ou constituindo empresas estatais para explorar diretamente a atividade econômica ou também para regular de forma indireta o desenvolvimento de quaisquer atividades econômicas (por exemplo, com a criação de uma agência reguladora independente).

(...)

Intervenção Estatal - a expressão deveria ser utilizada apenas quando se referisse às formas indiretas de atuação do Estado no domínio econômico ou quando explorasse diretamente atividade econômica de titularidade privada. Entretanto, é utilizada para representar qualquer maneira do Estado participar, intervir ou atuar no domínio econômico - esse é o significado de uso mais frequente (DEL MASSO, 2016, p. 80). 
O entendimento de Del Masso - no tocante à utilização do vocábulo intervenção para designar genericamente as várias modalidades de atuação do Estado no domínio econômico - se assemelha ao de Eros Grau (2015, p. 90-91):

(...) Daí se verifica que o Estado não pratica intervenção quando presta serviço público ou regula a prestação de serviço público. Atua, no caso, em área de sua própria titularidade, na esfera pública. Por isso mesmo dir-se-á que o vocábulo intervenção é, no contexto, mais correto do que atuação estatal: intervenção expressa atuação estatal em área de titularidade do setor privado; atuação estatal, simplesmente expressa significado mais amplo. Pois é certo que essa expressão, quando não qualificada, conota, inclusive, atuação na esfera do público.

(...)

Intervenção indicada em sentido forte (isto é, na sua conotação mais vigorosa), no caso atuação estatal em área de titularidade do setor privado; atuação estatal, simplesmente, ação do Estado tanto na área de titularidade de própria quanto em área de titularidade do setor privado. Em outros termos, teremos que intervenção conota atuação estatal no campo da atividade econômica em sentido estrito; atuação estatal, ação do Estado no campo da atividade econômica em sentido amplo.

O jurista em destaque defende que o vocábulo intervenção corresponderia única e exclusivamente aos casos em que se identificaria a atuação estatal no campo da atividade econômica em sentido estrito, ou seja, na área de titularidade do setor privado.

Partindo dessa premissa, Eros Grau (2015, p. 143) subdivide as formas de intervenção em (i) intervenção por absorção ou participação, (ii) intervenção por direção, e (iii) intervenção por indução.

Tem-se, então, no cenário jurídico as figuras da intervenção por absorção ou participação, nas ocasiões em que o Estado venha a atuar no domínio econômico e a intervenção por direção ou indução quando a atuação ocorrer sobre o domínio econômico. 
E, em função do tipo de identificação, pode-se atribuir ao Estado duas denominações técnicas: a de (i) agente econômico (quando promovesse intervenção no domínio econômico) e a de (ii) regulador da atividade econômica (quando promovesse qualquer tipo de intervenção sobre o domínio econômico).

Apresentadas essas considerações e, embasando-se em toda a doutrina analisada até aqui, já é possível discriminar, com certa tranquilidade, as formas de intervenção do Estado em relação ao domínio econômico:

(i) intervenção por absorção - forma de atuação no domínio econômico, através da qual o Estado assume o controle de um setor do mercado sob o regime de monopólio;

(ii) intervenção por participação - forma de atuação no domínio econômico, através da qual o Estado mantém empresas que disputam o mercado com o setor privado; (iii) intervenção por direção - forma de atuação sobre o domínio econômico, por meio da qual o Estado estabelece normas de conduta para os agentes do setor privado e,

(iv) intervenção por indução - forma de ação sobre o domínio econômico, por meio da qual o Estado estabelece políticas de benefícios fiscais ou tributários para os agentes do setor privado.

Por derradeiro, não se poderia deixar de mencionar que Bagnoli (2013, p. 109-110) afirma existir, além daquelas reconhecidas pela doutrina (direta e indireta), uma terceira espécie de atuação do Estado junto à atividade econômica; a qual denominou atuação por eleição:

(...) Outra forma de atuação dos Estado que se deve notar é a qual optamos designar atuação por eleição. Nessa, o Estado elege a grande empresa que atuará como uma 'global player' e receberá apoios institucionais e legais, além do imprescindível financiamento público, para enfrentar suas rivais no mercado nacional [muitas vezes até tornando esse mercado inviável para concor- 
rentes], mas sobretudo, na concorrência global. Criam-se, assim, as 'campeãs nacionais', grandes empresas concentradas, dependentes da influência política para consolidá-las internamente e para viabilizar o seu ingresso nos mercados internacionais. $\mathrm{Na}$ história recente do país destacam-se os financiamentos do Banco Nacional de Desenvolvimento Econômico e Social - BNDES - que viabilizaram: [i] a compra da Brasil Telecom pela Oi/Telemar; [ii] a compra da Aracruz pela Votorantim; [iii] a compra do Bertin pelo JBS; [iv] a compra da Sadia pela Perdigão; e [v] a compra da Biosin-tética pela Aché, além da atuação da Petrobrás que subsidiou a consolidação da petroquímica com a compra da Quattor pela Braskem [Odebrescht].

Como se constata, não remanesce dúvida alguma de que o legislador constitucional atribuiu ao Estado um verdadeiro poder/dever para com o desenvolvimento da ordem econômica do país.

Seja de forma direta seja indireta - por meio das várias modalidades de intervenções estudadas -, sabe-se que a criação de normas e a implementação de políticas públicas são hoje uma das principais ferramentas institucionais e jurídicas para se assegurar o cumprimento dos princípios e fundamentos estabelecidos no artigo $1^{\circ}$., III e IV, da Constituição Federal. ${ }^{9}$

\section{OS LIMITES CONSTITUCIONAIS DAS INTERVENÇÕES, SOB A Perspectiva do Poder Judiciário}

No item anterior, discorreu-se sobre os conceitos e as formas de atuação do Estado junto à atividade econômica do país.

9 art. $1^{\circ}$. A República Federativa do Brasil, formada pela união indissolúvel dos Estados e Municípios e do Distrito Federal, constitui-se em Estado Democrático de Direito e tem como fundamentos: (...) III - a dignidade da pessoa humana. IV - os valores sociais do trabalho e da livre iniciativa. 
Demonstrou-se, também, que o vocábulo intervenção vem sendo utilizado (preferencialmente) pela doutrina para representar essas formas (direta ou indireta) de atuação.

Seja por meio da intervenção por absorção (monopólios), por participação (serviços públicos); por direção (normatização das condutas dos agentes) ou, por indução (benefícios fiscais e tributários), fato é que o Estado, desde 1934, tem atuado de forma cada vez mais contundente no setor econômico do país. "Planos econômicos, tabelamentos de preços, políticas de privatização, de incentivos fiscais, políticas agrícolas, industriais de exportação, demarcação do espaço público e do privado são exemplos de ações estatais (...)" (AGUILLAR, 2016, p. 201).

Porém, haveria um limite constitucional para essa atuação? O Estado poderia, em nome do desenvolvimento e do bem-estar social, implementar políticas econômicas contrárias, por exemplo, ao direito adquirido, à propriedade privada, à livre iniciativa e à livre concorrência?

Decorridos quase 30 anos de entrada em vigor da atual Constituição Federal, a questão sobre esses limites ainda é tema dos mais controvertidos. Encontram-se juristas que defendem fervorosamente diminuição da atuação em privilégio à livre regulação do mercado e, outros tantos, que sustentam a importância do Estado intervencionista.

A todas essas indagações, ainda deve-se acrescer mais uma: Qual a perspectiva do Poder Judiciário sobre o assunto? Quais são os paradigmas jurisprudenciais sobre esses limites?

A reflexão é fundamental, uma vez que, tanto os julgamentos, quanto as decisões judiciais nessa seara não são muito constantes.

Segundo Aguillar (2016, p. 202-203), o fenômeno negativo, ou seja, essa ausência de paradigmas judiciais, teria uma explicação histórica:

(...) Durante os mais de 300 anos da regulação patrimonialista no Brasil, os tribunais não eram destinados a atender os reclamos de interessados em contrariar as políticas públicas dos donos do poder. Os tribunais não se destinavam a isso, porque o direito não se prestava a controlar os governantes.

(...) 
Dos 60 anos do período de regulação concentrada, mais de 36 correspondem a períodos de regime autoritário. Motivo adicional para não se recorrer ao Judiciário, especialmente para se questionar ações dos governantes. $\mathrm{Na}$ vigência da Constituição de 1937, a palavra final sobre a interpretação da lei e da Constituição deixou de pertencer ao Judiciário. Francisco Campos sustentava (...). No período militar, muito menos teve liberdade o Judiciário para manifestar suas opiniões.

É na transição para o regime democrático, no momento em que o eterno flagelo brasileiro da inflação atinge níveis insuportáveis, que medidas estatais radicalmente interventivas são adotadas e mais intensamente questionadas em juízo. É, portanto, um fenômeno muito recente na história brasileira a discussão judicial da Ordem Econômica constitucional.

Assim, somente no final da década de 80, quando o país se encontrava em uma profunda crise financeira - que, diga-se de passagem, obrigou o Estado a agir mais ostensivamente (por meio de uma política de congelamento de preços; proibições a saques das cadernetas de poupança, aplicações financeiras, além de outras medidas [impopulares] desproporcionais aos fundamentos e princípios constitucionais) - é que o Poder Judiciário passou a analisar, de forma mais contínua e amiúde, os limites dessas atuações.

Para se atingir o objetivo deste trabalho, foram estudadas as decisões originadas de dois julgamentos realizados pelo Supremo Tribunal Federal sobre questões vinculadas aos limites constitucionais das intervenções governamentais.

A primeira análise teve por objeto a decisão proferida no julgamento da AÇÃO DIRETA DE CONSTITUCIONALIDADE (ADI $\left.\mathrm{n}^{\circ} .1 .950\right)$ - que reconheceu a constitucionalidade da Lei Estadual $\mathrm{n}^{\circ}$. 7.844/94 (regulamentava o benefício da "meia-entrada" aos estudantes paulistas) e a segunda apreciou o acórdão resultante do julgamento da ARGUIÇÃO DE DESCUMPRIMENTO DE PRECEITO FUNDA- 
MENTAL (ADPF n $\left.{ }^{\circ} .46\right)^{10}$ que declarou a recepção (constitucionalidade) da Lei Federal nº. 6.538/78 (instituição do monopólio da Empresa Brasileira de Correios e Telégrafos [ECT]) pela Constituição de 1988.

Em relação ao primeiro caso, mereceram destaque os entendimentos divergentes dos ministros Eros Grau e Marco Aurélio de Melo.

Pelo entendimento defendido pelo ministro relator do acórdão (Eros Grau), o Estado possuiria uma função fundamental e, não poderia se portar como mero coadjuvante ou simples espectador no tocante aos assuntos pertinentes à Ordem Econômica: ${ }^{11}$

\begin{abstract}
“(...) No caso, se de um lado a Constituição assegura a livre iniciativa, de outro determina ao Estado a adoção de todas as providências tendentes a garantir o efetivo exercício do direito, à educação, cultura e ao desporto (artigos 23, inciso V, 205, 208, 2015 e $217 \S 3^{\circ}$., da Constituição). Ora, na composição entre esses princípios e regras há de ser preservado o interesse da coletividade, interesse público primário. A superação da oposição entre os desígnios de lucro e de acumulação de riqueza da empresa e o direito ao acesso à cultura, ao esporte e ao lazer, como meio de complementar a formação dos estudantes, não apresenta maiores dificuldades".
\end{abstract}

Pela leitura do trecho extraído do julgado, nota-se que o ministro posicionou-se no sentido de que a intervenção no domínio econômico não era apenas adequada, mas, também, indispensável para os alicerces do sistema (capitalista) escolhido pela Constituição de 1988, pois, ele (Estado) - por meio da elaboração e implementação de normas próprias - era que garantiria a sua equidade, evitando qualquer tipo de desequilibro gerado pelo eventual abuso do poder econômico.

O julgador afirmou que ofundamento da livre iniciativa (estabeleci-

10 Fonte: http://www.stf.jus.br. Acesso em 25-10-2016.

11 Trecho extraído do voto (vencedor) proferido pelo Ministro Eros Grau na ADI no 1.950 - julgamento realizado em 03-11-2005 - fonte: http:/www.stf.jus.br. Acesso em 19-10-2016. 
do no caput do artigo 170) e o princípio da livre concorrência (previsto no inciso IV, do mesmo dispositivo constitucional), não eram absolutos quando defrontados com o interesse da coletividade (fim social).

Em posição oposta permaneceu o ministro Marco Aurélio de Mello - ao julgar procedente o pedido de inconstitucionalidade da lei paulista -. Sob o seu ponto de vista, o Estado de São Paulo, ao editar o dispositivo legal, o fez em total contrariedade aos fundamentos do artigo 170 , da $\mathrm{CF} / 88$, principalmente aquele que versava sobre a livre iniciativa: ${ }^{12}$

(...) Não vejo como se estabelecer, e de forma linear, o que apontei como gratuidade parcial, a meia-entrada para ingresso em espetáculos diversificados. Não vejo como se fixar esse ônus, que acaba sendo suportado, ante a transferência, pela sociedade, tendo em conta a majoração da entregada para aqueles que não gozam do benefício, mediante uma norma, repito, não razoável, porque nela se contém a contrapartida, ou seja, uma compensação - havendo uma desvantagem significativa - da perda por aqueles que se lançam no mercado, na vida comercial, e precisam fugir à morte civil nessa mesma vida comercial, que é a falência.

Evidencia-se no posicionamento transcrito certo inconformismo, já que, para esse julgador, o Estado teria editado uma norma comportamental, impondo aos empresários (que desenvolviam atividade no seguimento), circunstâncias desfavoráveis, sem, ao menos, lhes oferecer uma contrapartida, tais como isenção de impostos, taxas etc.

O ministro derrotado chegou, inclusive, a afirmar que o Estado de São Paulo teria instituído benefícios aos estudantes, com o "chapéu alheio" o que, em tese, fugiria aos princípios constitucionais.

12 Trecho extraído do voto (vencido) proferido pelo Ministro Marco Aurélio de Mello na ADI $n^{\circ} .1 .950$ - julgamento realizado em 03-11-2005 - fonte: http://www.stf. jus.br. Acesso em 19-10-2016. 
Nota-se, no último entendimento, uma postura menos intervencionista, totalmente distinta da anterior, contudo, prevaleceu o entendimento do ministro Eros Grau e, a ação foi julgada improcedente.

Diante do resultado do julgamento, e de toda a discussão doutrinária que o antecedeu, constatou-se que a Corte Maior (naquela ocasião) apresentou uma postura menos liberal; voltada a garantir a intervenção governamental no domínio econômico, afastando, inclusive, a possibilidade de se considerarem absolutos, tanto o fundamento da livre iniciativa, como o princípio da livre-concorrência.

E mais, não poderia deixar de se mencionar que o resultado desse julgamento serviu de precedente para o deslinde de outra ação semelhante, qual seja, AÇÃO DIRETA DE INCONSTITUCIONALIDADE - ADI $n^{0} .3 .512^{13}$ (cuja lei estadual em análise concedia o benefício da meia-entrada para os doadores de sangue no Estado do Espírito Santo) e, provavelmente, servirá de paradigma para a solução da ADI $2163^{14}$ (cuja lei estadual em análise instituía a meia-entrada para os menores de 21 anos de idade do Estado do Rio de Janeiro).

Feitas as considerações sobre o primeiro caso (intervenção por direção), disserta-se, agora, acerca dos resultados obtidos com o segundo (intervenção por absorção), correspondente à decisão proferida na ADPF $n^{\circ} .46$, que reconheceu a compatibilidade da Lei Federal $n^{\circ}$. 6.538/78 com o texto constitucional de 1988 .

No entendimento da ABRAED - ASSOCIAÇÃO BRASILEIRA DAS EMPRESAS DE DISTRIBUIÇÃO (autora da ação judicial, em questão), a Lei $n^{\circ}$. 6.538/78 não poderia ser recepcionada pela Carta Magna, justamente por não respeitar os fundamentos e os princípios da livre concorrência e o da livre iniciativa (artigo 170, caput e IV) em relação à prestação dos serviços postais e de entrega de mercadorias.

Ou seja, se a pretensão fosse julgada procedente, o monopólio estaria desfeito e as empresas privadas poderiam atuar livremente no setor, sem qualquer imposição de penalidades.

13 Julgada improcedente. Julgamento realizado em 15-02-2006 - fonte: http://www. stf.jus.br. Acesso em 19-10-2016.

14 O processo encontra-se concluso com o ministro Luiz Fux e aguarda julgamento fonte: http://www.stf.jus.br. Acesso em 19-10-2016. 
O relator do caso (ministro Marco Aurélio de Mello) acolheu o pedido por entender que aquela legislação, de fato, violava os preceitos estabelecidos no texto constitucional. ${ }^{15}$

No entanto, o ministro Eros Grau, ${ }^{16}$ novamente, apresentou um posicionamento diferente, afirmando, inclusive, que os serviços postais não poderiam ser conceituados juridicamente como monopólio, mas, sim "serviço público" e que, portanto, deveriam receber um tratamento privilegiado:

(...) Tenho reiteradamente insistido na necessidade de apartarmos o regime de privilégio, de que se reveste a prestação dos serviços públicos, do regime de monopólio, sob o qual, algumas vezes, a exploração de atividade econômica em sentido estrito é empreendida pelo Estado.

Monopólio é de atividade econômica em sentido estrito. Já a exclusividade da prestação dos serviços públicos é expressão de situação de privilégio. (...)

(...)

O serviço postal é prestado pela Empresa Brasileira de Correios e Telégrafos, empresa pública, entendida da Administração Indireta da União, como tal criada pelo decreto-lei n. 509, de 10 de março de 1.969, que foi recebido pela Constituição de 1988. Atua, isto é, deve atuar em regime de exclusividade na prestação dos serviços que lhe incumbem, ou seja - em linguagem técnica correta - em situação de privilégio [o privilegio postal] ou - na linguagem corrente - em regime de monopólio.

Quanto ao âmbito do serviço postal, está bem desenhado nos artigos $7^{\circ}$ e seguintes da Lei n. 6.358/78, também recebida pela Constituição de 1.988 .

15 Fonte: http://www.stf.jus.br. Acesso em 25-10-2016.

16 Trecho extraído do voto do ministro Eros Grau no julgamento da ADPF n ${ }^{\circ} .46-$ julgamento em 05-08-2009 - fonte: http://www.stf.jus.br. Acesso em 25-10-2016. 
Nota-se que o entendimento vencedor também teve por fundamento o comando legal inserido nos artigos 199 e 209, da atual Constituição, destacando o fato de que, se o legislador constitucional desejasse que os serviços postais fossem transferidos à livre iniciativa, o teria realizado como o fez com a saúde e educação.

Observa-se, ainda, no trecho do voto transcrito, que se fez uma severa distinção entre o conceito de serviço público e monopólio, circunstância que alteraria, completamente, o resultado do julgamento, pois ressalvado o ministro relator, todos os demais julgadores seguiram o posicionamento de Eros Grau (em relação aos conceitos e ao regime de privilégio).

Alguns ministros, entre eles, Carlos Britto, ${ }^{17}$ apenas divergiram de Eros Grau em relação à natureza dos serviços postais que poderiam ser considerados privilegiados:

(...) E qual seria a razão, a finalidade de a Constituição tratar a matéria por uma forma tão diferenciada? Essa especifidade decorreria da destinação das atividades de que estamos a falar: favorecer a comunicação privada entre pessoas, a integração nacional e o sigilo de correspondência. Que correspondência? Correspondência epistolar e telegráfica, porque essas são cercadas, pelo inciso $\mathrm{X}$ do artigo $5^{\circ}$ da Constituição quer invioláveis a correspondência epistolar e a comunicação telegráfica, por isso reservou tais atividades para esse senhorio exclusivo e protogonização também exclusiva da União. (...)

Senhor Presidente, neste primeiro momento inclino-me por entender que essa exclusividade a qual me refiro circunscreve-se às atividades que impliquem comunicação privada e comunicação telegráfica. Aquilo que tiver caráter rigorosamente mercantil, comercial, eu excluiria dessa atividade da União.

17 Trecho extraído do voto do ministro Carlos Brito no julgamento da ADPF n ${ }^{\circ} .46-$ julgamento 03-11-2005 - fonte: http://www.stf.jus.br. Acesso em 25-10-2016. 
Vê-se no entendimento do ministro Britto uma postura mais intervencionista que a do próprio Eros Grau, pois, enquanto este defende (apenas) a existência e manutenção do privilégio, aquele adentra no campo restrições, discriminando quais serviços fariam parte da prestação exclusiva da União, excluindo do rol todos os que tivessem caráter rigorosamente mercantil e comercial, como a entrega de encomendas, encartes publicitários, boletos bancários etc.

Ou seja, seguindo a mesma linha do julgamento proferido na ADI $n^{\circ}$. 1.950, o Superior Tribunal Federal anuiu, mais uma vez, com a possibilidade de o Estado intervir (sem grandes restrições) no domínio econômico.

Ao reconhecer a constitucionalidade da Lei $n^{\circ}$. 6.538/78, a Corte Maior não só ratificou os atos governamentais pretéritos, advindos de uma época ditatorial, como também assinalou sua tendência, qual seja, a de mitigar o princípio da livre concorrência e o fundamento da livre iniciativa, em benefício dos interesses da coletividade, representada, no caso, pelo Estado.

Após a análise pormenorizada das decisões proferidas nos julgamentos em destaque, identificou-se uma forte complacência em relação à extensão dos limites das intervenções; remanescendo incontroverso que, quando os interesses da coletividade estivessem em discussão, o Estado poderá interferir direta ou indiretamente na área econômica, seja pela absorção, participação (atuação na atividade econômica em sentido estrito), direção ou indução (edição de normas reguladoras comportamentais).

\section{CONSIDERAÇões FINAIS}

A partir de 1934, o legislador passou a inserir nos textos das Constituições brasileiras normas de natureza econômica, destacando-se, neste aspecto, a Carta de 1988, que destinou um título e quatro capítulos (exclusivos) para regulamentar a Ordem Econômica e Financeira.

Seja por meio de intervenções diretas ou indiretas; a atuação do Estado no domínio econômico do país (mediante a implementação de 
planos econômicos, políticas de privatizações, incentivos fiscais, tabelamentos de preços etc); tornou-se uma realidade constante.

Contudo, a discussão sobre os limites dessas intervenções sempre foi tema recorrente nos meios jurídicos.

Sabendo-se que toda ordem jurídica estabelece os seus próprios limites, qual seria a perspectiva do Poder Judiciário sobre essa intrincada questão?

Para tentar responder a essa indagação, em um primeiro momento dissertou-se, em linhas gerais, sobre os conceitos de Direito Econômico; Ordem Econômica e Constituição Econômica.

Depois, apresentaram-se os principais fatos históricos que levaram à sistematização da Ordem Econômica e Financeira no texto constitucional atual e, por derradeiro, discorreu-se sobre as formas de Intervenção do Estado no domínio econômico concebidas pela doutrina brasileira (intervenção por absorção [monopólios], por participação [serviços públicos]; por direção [normatização das condutas dos agentes] ou, por indução [benefícios fiscais e tributários].

Superada a primeira etapa do trabalho, passou-se, então, a discorrer sobre o resultado obtido com o estudo dos acórdãos proferidos pelo Supremo Tribunal Federal nos julgamentos (AÇÃO DIRETA DE CONSTITUCIONALIDADE [ADI $n^{\circ}$. 1.950] e da ARGUIÇÃO DE DESCUMPRIMENTO DE PRECEITO FUNDAMENTAL [ADPF $\mathrm{n}^{\circ}$. 49]) que, diga-se de passagem, ganharam grande destaque no cenário jurídico nacional em razão da temática envolvida.

Após a análise das decisões e, frente a toda discussão doutrinária que as antecederam, constatou-se que a Corte Maior, ao contrário do que muitos juristas imaginavam na ocasião, manteve um entendimento conservador; voltado a garantir a intervenção governamental no domínio econômico, afastando, inclusive, a possibilidade de se considerarem absolutos, tanto o fundamento constitucional da livre iniciativa quanto o princípio da livre-concorrência.

Da pesquisa realizada, também se identificou na postura dos ministros - que naquele momento integravam o Supremo Tribunal Fede- 
ral - uma maior permissividade (elasticidade), certo afrouxamento, por assim dizer, em relação aos limites constitucionais para as intervenções.

Pelo teor dos julgamentos, restou evidente que, nas hipóteses em que os interesses da coletividade estivessem em discussão, o Estado poderia e poderá, mediante a edição de leis de natureza específica (econômica), interferir direta ou indiretamente na área econômica.

Logicamente a celeuma está longe de ser resolvida, pois a discussão judicial de questões voltadas à Ordem Econômica constitucional é muito recente na história jurídica do país.

Somente a partir do final da década de 80 , ou seja, no apagar das luzes do século passado, é que as medidas intervencionistas passaram a ser questionadas judicialmente com maior recorrência.

Hoje, outras questões de natureza econômica (Políticas Públicas de Saúde, Educação etc.) já ganham destaque nos Tribunais pátrios, circunstância que obrigará tanto os juristas, quantos os cientistas políticos e econômicos a se debruçarem, com mais afinco, sobre o tema.

Espera-se, assim, que, com o passar do tempo, as decisões judiciais referentes ao Direito Econômico (nas mais variadas instâncias) tornem-se mais frequentes e venham a contribuir para a criação de um paradigma jurisprudencial consistente.

\section{REFERÊNCIAS}

BAGNOLI, Vicente. Direito econômico, 6. ed. São Paulo: Atlas, 2013.

BRASIL. Constituição (1988). Constituição da República Federativa do Brasil, 53. ed. São Paulo: Saraiva, 2016.

DEL MASSO, Fabiano. Direito Econômico esquematizado, 4. ed. São Paulo: Método, 2016.

FONSECA, João Leopoldino. Direito econômico, 6. ed. São Paulo: Malheiros, 2010.

GRAU, Eros Roberto. A ordem econômica na constituição de 1988, 17. ed. São Paulo: Malheiros, 2015. 
MOREIRA, Vital. Economia e constituição: para o conceito de Constituição econômica. Coimbra: Faculdade de Direito, 1974.

SILVA, José Afonso. A aplicabilidade das normas constitucionais, 8. ed. $2^{\text {a }}$. tiragem. São Paulo: Malheiros, 2015.

SOUZA, Washington Peluso Albino. Primeiras linhas de direito econômico, 5. ed. São Paulo: LTr, 2003.

TAVARES, André Ramos Tavares. Direito constitucional econômico. São Paulo: Método, 2011.

Website: http://www.stf.jus.br. Acessos em 15.08.2016; 18.08.2016; 13.09.16; 19.10.2016 e 25.10 .2016 .

Dados do Autor

\section{Washington Eduardo Perozim da Silva}

Bacharel em Ciências Jurídicas e Sociais pela Pontifícia Universidade Católica de Campinas. Mestrando em Direito pela Universidade Metodista de Piracicaba/SP. Professor de Direito Civil e Direito Empresarial na Devry/Metrocamp. Piracicaba/SP - Brasil. washington@perozim.com.br

Submetido em: 22-02-2017

Aceito em: 05-04-2017 